\title{
SINIS - A method to support defining goals, strategies and indicators for IT Services
}

\author{
Bianca Trinkenreich ${ }^{1}$, Gleison Santos ${ }^{1}$, Monalessa Perini Barcellos ${ }^{2}$ \\ ${ }^{1}$ Programa de Pós-Graduação em Informática, Departamento de Informática Aplicada, \\ Universidade Federal do Estado do Rio de Janeiro (UNIRIO), Rio de Janeiro, Brasil \\ ${ }^{2}$ Núcleo de Estudos em Modelagem Conceitual e Ontologias (NEMO), Departamento de \\ Informáica, Universidade Federal do Espírito Santo (UFES), Vitória, ES, Brasil \\ \{bianca.trinkenreich, gleison.santos\} duniriotec.br, \\ monalessa@inf.ufes.br
}

\begin{abstract}
Measurement is a key process to support organizations in management and improvement of processes, products and services. IT services literature states that indicators need to be aligned with goals and critical business processes to proper support decision-making. However, IT service departments often spend time and effort measuring without being sure about what the measurement results represent. In this paper, we present SINIS, a method to support defining goals, strategies and indicators for IT Services. We designed SINIS through incremental learning cycles during multiple qualitative studies and applied it in IT Security area of a global large company By using SINIS, organization could better align goals, strategies and indicators, and discard those not considered useful.
\end{abstract}

\section{Introduction}

A service is about delivering value to customers by facilitating results customers want to achieve, without the ownership of specific costs and risks. IT service management is a set of specialized organizational capabilities for providing value to customers through services. Its practice has been growing by adopting an IT management service-oriented approach to support applications, infrastructure and processes [TSO, 2011].

Guidance on how to develop and improve IT service maturity practices is a key factor to improve service performance and customer satisfaction [FORRESTER et. al., 2010) . CMMI-SVC [FORRESTER et. al., 2010) and MR-MPS-SV [SOFTEX, 2015] models were created to attend this need and are based on more traditional models like ITIL [TSO, 2011] and international standards such as ISO/IEC 20000 [ISO, 2001]. These models require appropriate measures to be identified to monitor various processes executed for service delivering to customers. Thus, selection of sub-processes to be measured must be aligned with organizational goals so measurements results are able to deliver relevant information for decision making and business support. However, there is no clear direction or strict suggestion about which business processes and measures should be considered.

Considering that an indicator is a measure that embodies a strategic objective and measures performance against a goal [BARCELLOS et. al, 2012], even having a list of measures, it is still not easy to align them to goals and define indicators for IT 
services [PARMENTER, D., 2015]. Alignment demands understanding stakeholders' information needs and the way IT services processes were designed and are executed in the organization, detecting IT services critical processes and choosing strategies that should be followed by IT services to achieve established goals. Therefore, a method that includes a measure database for reuse can reduce effort and speedup selection [KANEKO et al, 2011] [JANTTI et al, 2010] [KILPI, T., 2001]. One of the seven foundation stones that need to be laid before a successful measurement initiative is to measure only what matters [PARMENTER, D., 2015]. In this sense, we developed SINIS (Select Indicators for IT Services), a method to support selection of indicators for IT services aligned with organization goals. SINIS is based on GQM+Strategies [BASILI et. al., 2005], COBIT Goal Cascade [ISACA, 2012], business process modeling of IT services, a list of measures for IT services [TRINKENREICH et al, 2015a] and a Reference Software Measurement Ontology [BARCELLOS et al, 2012].

In this paper we present SINIS and some relevant aspects about its development and use. Section 2 provides a theoretical framework, Section 3 describes the followed research method, Section 4 presents SINIS, Section 5 describes the action research, Section 6 discusses some Related Works and Section 7 presents our final considerations.

\section{IT Service Quality and Measurement}

Service quality is an abstract concept due to the nature of "service" term, which is intangible, non-homogeneous and its consumption and production are inseparable. It can be understood as a measure about how much a service level meets or does not meet customers' requirements and expectations. The intangibility of services makes it difficult to understand how customers observe and evaluate their services quality [SOFTEX, 2015].

To offer quality, the supplier must continually assess the way in which services are provided and what customers expect in the future. Customers will be unsatisfied with IT service providers who occasionally exceeds expectations, but at other times they disappoint. Measurement plays a key role in process quality improvement initiatives. Through process and products data collection and analysis, measurements can quantitatively demonstrate their quality and decision making support. Being able to control and predict processes future behavior allows the supplier to increase probability of achieving the expected IT service quality.

IT service literature does not provide a strict direction about which processes and measures should be considered for measurement. Moreover, properly selecting measures and indicators is not a trivial task. Even if a measures database is available, it is still not easy to select the proper ones and identify indicators for IT services [PARMENTER, D., 2015]. Some factors contribute to the difficulty in selecting measures and indicators for IT services, such as: (i) lack of approaches to guide IT services indicators selection, (ii) lack of practical examples involving IT service indicators, and (iii) lack of measurement capabilities in IT supporting tools [JÄNTTI et al., 2010] [LEPMETS et al., 2014]. An available list of indicators can help being a start point for insights during measurement selection [TRINKENREICH et al, 2015a].

There are some approaches that deal with this issue. COBIT Goals Cascade [ISACA, 2012] provides a catalog with 17 enterprise goals and IT-related goals and 
more than 100 indicators to be reused. However, as different market situations and environments require different measures, COBIT recommends each enterprise should build its own cascade, compare it with COBIT and then refine it [ISACA, 2012]. Balanced Scorecard (BSC) [KAPLAN AND NORTON, 1996] applies measurement to verify if organization activities meet its goals with respect to vision and strategy. BSC does not provide an explicit way to define goals, strategies and indicators related to different organizational levels, being more used at higher levels. GQM+Strategies [BASILI et. al., 2005] is an extension of the GQM [SOLIGEN AND BERGHOUT, 1999], and takes strategies and measures as input for a model from the business level down to project and operational levels and back up. In that sense, GQM+Strategies focuses on filling organizations vertical gaps and helps creation of goals and strategies and deriving indicators that are aligned with high-level business goals. It also provides a mechanism to monitor success and failure of goals and strategies through measurement. The main components introduced by this approach [BASILI et. al., 2005] are: Organization goals (what the organization wants to achieve), Strategies (how to achieve goals), Context Factors (external and internal environments), Assumptions (unknown estimations), GQM graphs [SOLIGEN AND BERGHOUT, 1999] (how to measure if goals were reached and strategies succeed or failed) and Interpretation Model (consolidation of entire process of deriving business goals and GQM graphs [SOLIGEN AND BERGHOUT, 1999].

\section{The Research Method Followed to Create SINIS}

Primary research approach used is Design Science Research, which is the design and investigation of artifacts in context, designed to interact and improve something in that context (WIERINGA, 2014). Figure 1 depicts the Design Science Research Map of this researchThe proposed artifact is a method called SINIS, which in addition to the method itself, provides procedures, checklists, templates and examples that help its application. Steps followed to develop this research were:

i. Literature investigation to acquire knowledge about the research topic in order to identify the problem and delimit the research scope;

ii. Execution of design and investigative activities in incremental learning cycles aiming to obtain useful knowledge to develop SINIS:

ii.1. Systematic Mapping to find measures suitable for IT Services measurement initiatives (TRINKENREICH et al., 2015a);

ii.2. Action Research about IT Services Measurement Process and Measures (TRINKENREICH and SANTOS, 2014);

ii.3. Case Study to evaluate Measures found in by the Systematic Mapping and to investigate impact among IT Services processes (TRINKENREICH and SANTOS, 2015a);

ii.4. Case Study about using Business Process Intelligence for critical process analysis (TRINKENREICH et al., 2015b);

ii.5. Action Research about using critical process mapping and expected results of MRMPS-SV to evaluate an IT Services process and select indicators at different levels by using GQM+Strategies (TRINKENREICH and SANTOS, 2015b); 
ii.6. Case Study involving Qualitative Analysis to find about how operational actions, projects or initiatives are defined to achieve IT Services indicators.

iii. Development of the first version of the proposed solution and evaluation through a case study (TRINKENREICH et. al, 2015c);

iv. Evolution of the proposed solution and evaluation through an action research.

Requirements were established based on aspects pointed out in the literature. R1 was based on [KANEKO et al, 2011], [JANTTI et al, 2010] and [KILPI, T., 2001], which state that indicators selection can take a long time and suggest that reusing existent indicators can save cost and time and, also, inspire creating new ones. R2 and R3 were defined based on [BASILI et. al., 2005], which emphasizes that measurement must be aligned to organizational goals and that it is necessary to cover several organizational levels to provide useful information for each one of them and for the organization as a whole. Besides, the authors advocate the use of strategies as a way of achieving the established goals and the implementation of a measurement system to verify goals achievement and strategies failure or success. R4 was based on works that recommend the use of instruments to support measurement-related activities execution. BASILI et al. [BASILI et. al., 2005] suggest using questions for goals elicitation and categories for classifying goals. PETERSEN et al. [PETERSEN et. al, 2015], in turn, suggest semi-structured interviews as a complementary way to templates and notations for getting information regarding goals, strategies or indicators. Finally, R5 considered the works by BARCELLOS et al. [BARCELLOS et al, 2012], which discuss problems in measurement terminologies and point out the need of using a consistent terminology to promote common understanding. 


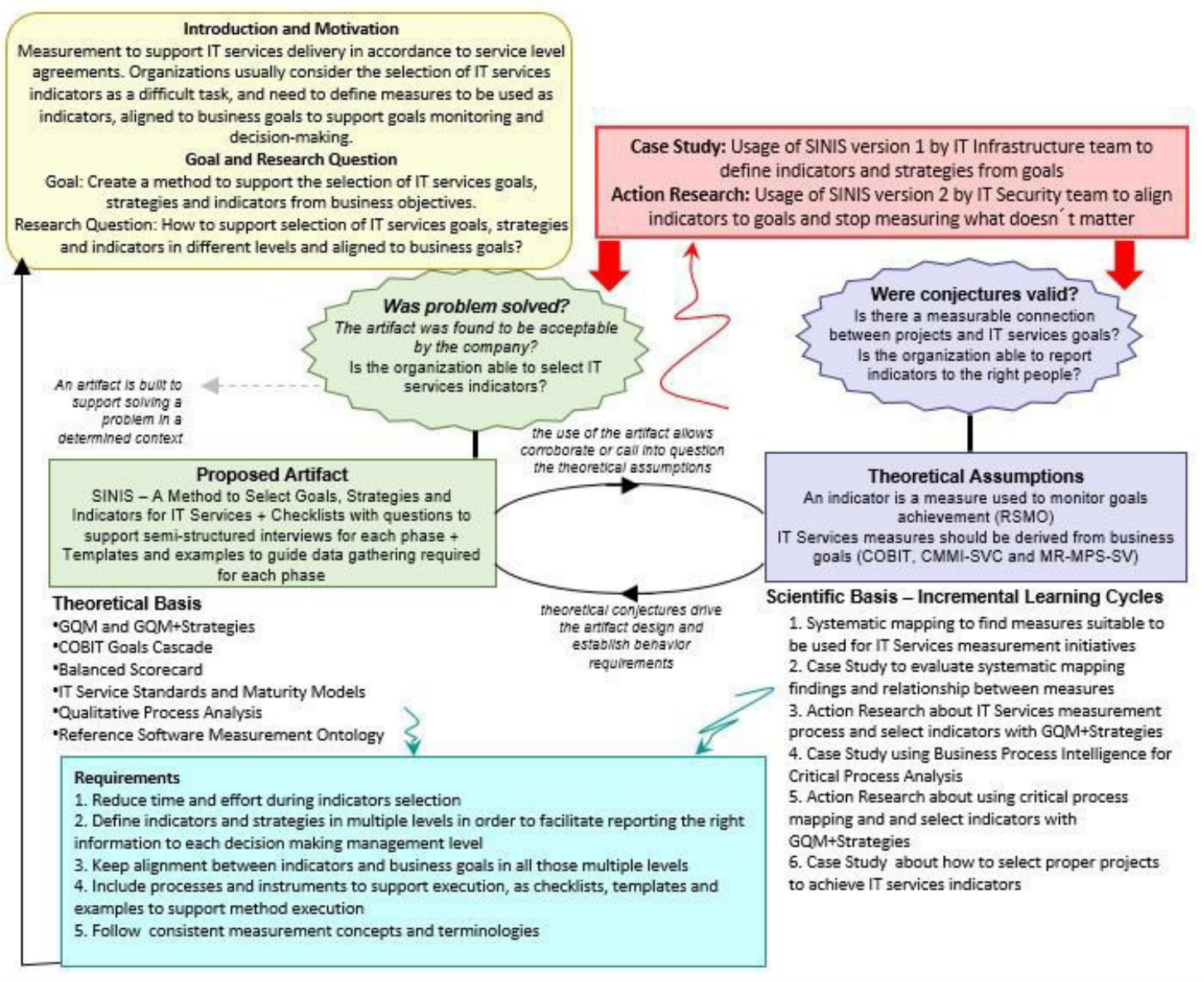

Figure 1 - Design Science Research Map and Dissertation Structure (based on [31])

\section{SINIS - A method to support defining goals, strategies and indicators for IT Services}

SINIS is a method to help organizations in defining goals and indicators for IT services in alignment to business goals. By doing that, the method provides information about strategies, projects, initiatives or actions that contribute to goals achievement. As discussed in the previous sections, SINIS reuses knowledge provided by other proposals and it is mainly based on the GQM+Strategies (BASILI et al., 2005) and COBIT Goals Cascade [ISACA, 2012]. SINIS consists of a process containing a set of activities to be accomplished to select relevant IT service indicators, and a set of templates, checklists and examples to support activities execution. Figure 2 shows a summarized overview of SINIS, composed of four phases. As follows we describe SINIS phases and activities. [TRINKENREICH et.al, 2015c]

(i) Elicit IT Services Context Factors and Assumptions: Both IT Service Goals and Strategies are defined in organization context, where options are limited by organization specific capabilities, issues or constraints. We start method by collecting context factors and assumptions for specified organization, to use them since the beginning for aligning IT service goals and strategies [BASILI et. al., 2005]. Context factors are aspects factually known (e.g., organization $\mathrm{X}$ needs to improve service availability) and assumptions are aspects believed to be true but have little or no evidence about (e.g., in 
organization X IT Services costs cannot be increased). Organization's business plans and current budget, goals and objectives set by business, targets and thresholds to maintain or achieve service levels and service level agreements are some of the various sources of information that are relevant to IT Services measurement process [BROOKS, P., 2006]. Several sources can be used as critical success factors, vision and mission statements, organizational goals, internal and external constraints, market trends, opportunities, staff competences, technological advances, contacts and infrastructure. If documents are not available, meetings with organization stakeholders can be used to gather information.

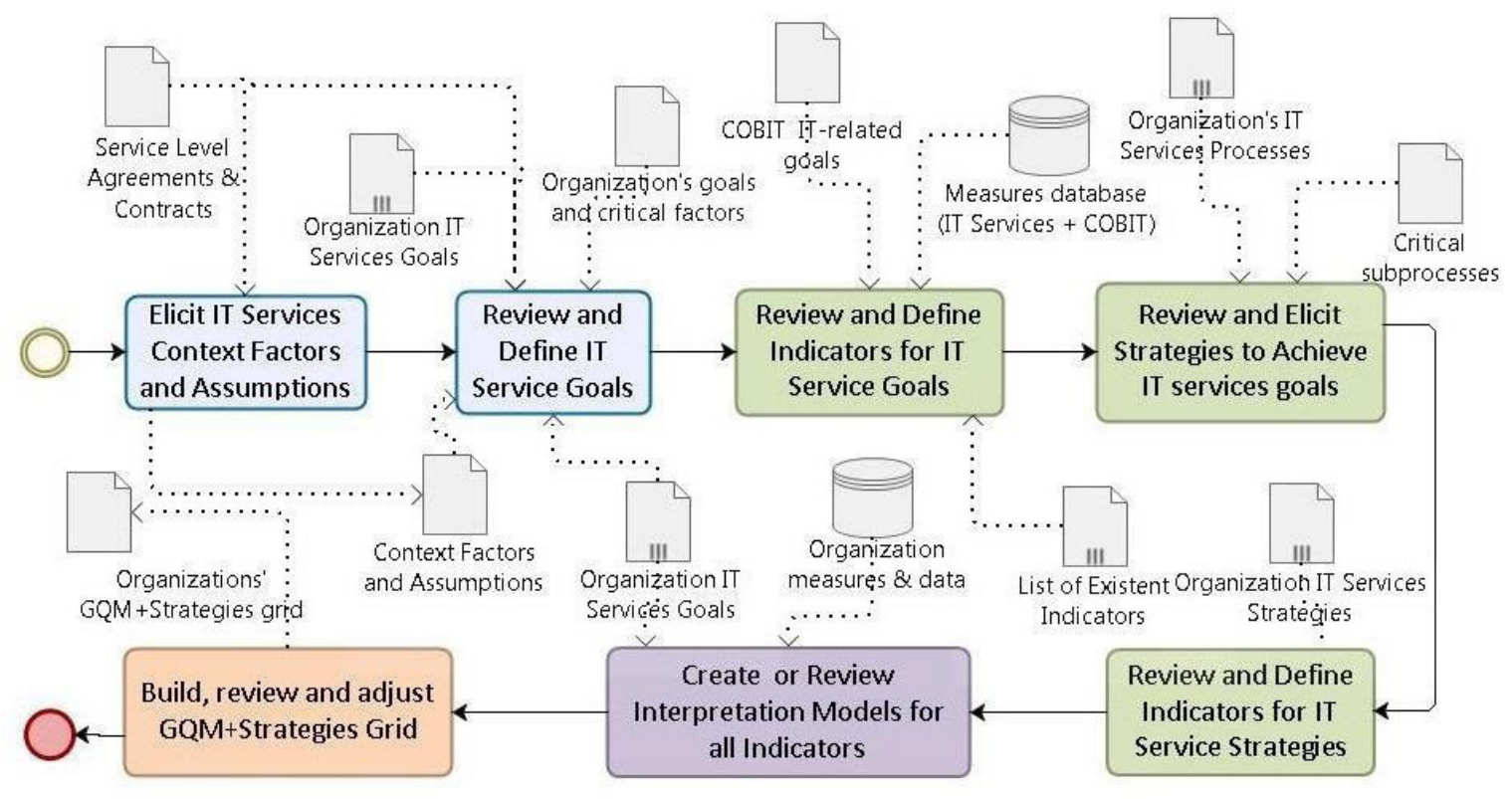

Figure 2 - SINIS

(ii) Review and Define IT Service Goals: This phase concerns about gathering, creating and reviewing IT services goals based on the organizational goals. Moreover, it addresses the definition of indicators to monitor the identified IT service goals. If Organization does already have a list of existent IT Service Goals and just need to associate indicators to goals, goal are gathered and reviewed. If not, they are defined. IT service goals should be defined to be Measurable and Achievable [BASILI et. al., 2005], and also Specific, Relevant and Time Sensitive, following all five SMART principles [DRUCKER, P., 1954]. Goals cannot be broad or vague, need to be broken down into specific results, written using words that clearly describe results that are trying to be achievable, which are going to be evidenced by indicators results [BARR, S., 2014]. During this activity, context factors and assumptions are used to support definition of IT Services goals. To reduce effort, saving cost and time, reuse is supported by consulting COBIT IT-related goals [ISACA, 2012] to verify whether they are applicable or can inspire new ones. Template is based on GQM+Strategies [BASILI et. al., 2005] and also requires information regarding the $\mathrm{BSC}$ dimensions related to the recorded goal. BSC dimensions were included in the template mainly because next activities involve searching for COBIT management practices and indicators, and COBIT Cascade Goals considers goal classification per BSC dimension.

(iii) Review and Define Indicators for IT Service Goals: During this phase, all indicators in use by organization are listed and briefly described to provide an initial 
understanding about their meaning. Indicators can be rewritten to have a clearer meaning and those ones not associated to any goal are discarded. Considering that indicators are already being collected and analyzed, data should be gathered from existent measurement documentation and meetings. If needed news indicators to measure a service goal achievement must be defined.

(iv) Review and Elicit Strategies to Achieve IT services goals: This phase concerns on providing strategies to achieve IT service goals. If the organization already has a list of existent IT service strategies, projects, initiatives or operational actions planned or in course to achieve IT services goals, they are gathered and reviewed. This activity can be executed by documentation analysis and open interview meetings with IT Services department manager and team. If not, they are going to be defined.

SINIS uses critical IT services process analysis to support definition of strategies to achieve IT service goals. Processes identified in last phase as being related to IT service goals are mapped and analyzed to find the critical processes to be focused by strategies. Besides the processes themselves, relationships between it and other processes are analyzed to help finding cause and effect for difficulties that the organization is having to achieve IT service goals.

Root cause analysis, sensitivity analysis, or process performance model can help to identify sub-processes that contribute the most to achieving goals (FORRESTER et. al., 2010). For example, if we need to reduce incident resolution time, besides doing process quality investigation, it would be useful to check incidents reports. Like that it would be possible to get which applications are causing the largest number of incidents, or incidents that had taken longer to be solved, to be addressed first. Since the use of Pareto diagrams is related to a known list of causes, problem and causes must be defined first.

Considering results of root-cause for qualitative processes analysis, strategies are established to achieve the IT Service goals. Established strategies will be implemented in projects, initiatives or even simple activities. General context factors and assumptions for IT Services were defined in SINIS' first activity. Now we elicit specific context factors and assumptions for strategies, and compare them with general context factors and assumptions to check if there is any incoherence that needs to be adjusted.

(v) Review and Define Indicators for IT Service Strategies: Similarly to activity (iii) Review and Define Indicators for IT Service Goals, strategies are made measurable by specifying appropriate questions and measurement plans to define indicators and how their data collection must be performed. Analogously to the cited activity, to reduce effort, saving time and cost, reuse is supported by consulting two sources: COBIT Process sample measures and IT Services list of measures to verify whether they are applicable or can inspire new ones. During this phase, all indicators in use by the organization to measure IT Service for Strategies are listed and described. Indicators can be rewritten for clearer meaning and those not associated to any goal are discarded. If organization finds that any new indicator is needed to measure a strategy achievement, they must be defined.

(vi) Define Interpretation Models for IT Service Goals and Strategies Indicators: During this phase, Interpretation models are defined to determine how data collected for 
the defined indicators should be interpreted to support informed decisions about strategies and IT services goals achievement. Targets can be defined based on previous service level agreement contracts and reports or business's needs. Some aspects that can be considered when defining Interpretation Models are expected result for this indicator to achieve related goal, between which range is the result considered as achieved, if the result is up/below the range considered as achieved, should it be interpreted as good or bad, how/when should the indicator be interpreted.

(vii) Build, review and adjust GQM+Strategies Grid: During this phase, context factors, assumptions, goals, strategies and indicators are organized in a GQM+Strategies grid aiming to provide an overview of IT services measurement and help validation and identification of review needs. Ideally, the grid must present the cleanest possible view. We provide SINIS template grid in Figure 2. We designed the template in a way to facilitate viewing different levels goals, strategies and indicators in a single page. In addition, general context factors and assumptions were disposed in this same single page, allowing to verify if they are current or changed. If it is necessary to change context factors and assumptions, the grid provide an easy view of goals, strategies and indicators that are impacted by the changes and might change. Although using the template we can show the grid in a single page, if there are many context factors, assumptions, goals, strategies and indicators and it is not viable to represent them in a single page, they can be organized in more than one by following the same proposed structure.

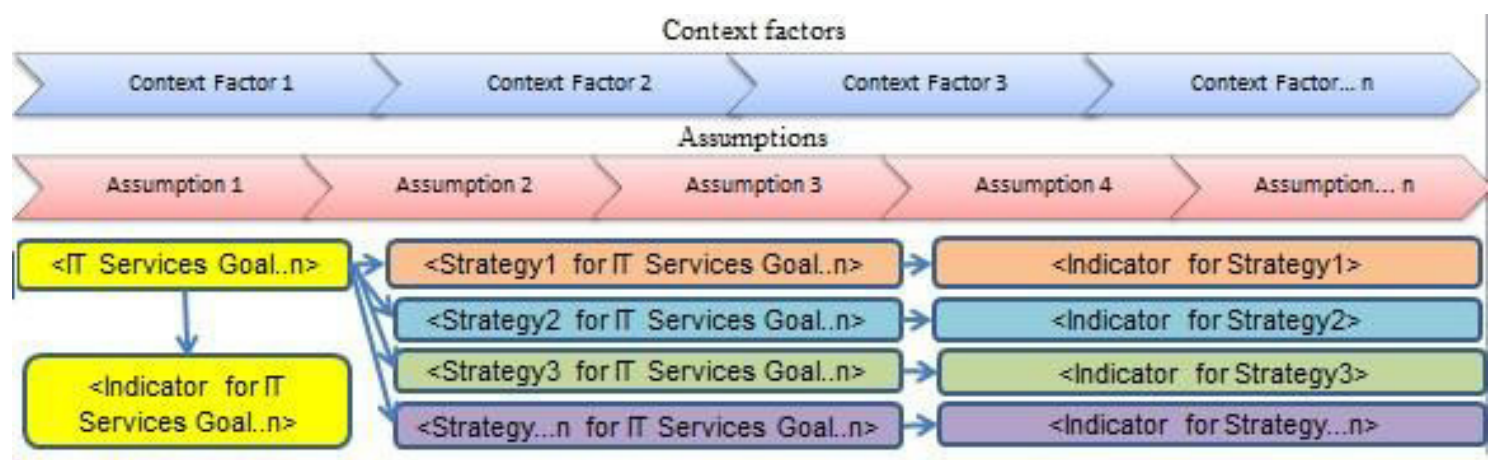

Figure 2 - SINIS template for GQM+Strategies grid [TRINKENREICH et.al, 2015c]

GQM+Strategies Grid and Interpretation Models must be presented to all stakeholders through meetings in which information sources, context factors and assumptions must be validated, and applicability, completeness, accuracy and consistency of goals, strategies and indicators must be evaluated. Also, discussions can point out potential findings and improvement opportunities. It is recommended to include people who were not involved in SINIS application, but will be eventually involved in established strategies, executing or being impacted by execution or results. During this phase, if any definition needs to be adjusted, it is possible to get back to where is necessary to make changes and then continue following method from that point until the end again. For example, if an IT service goal needs to be changed, the related measurement plan needs to be adjusted to reflect changes, respective interpretation model, and also strategies created to attend that goal need to be revisited (and of course 
respective measurement plan and interpretation models). Which mean that traceability is done to keep everything consistent after a change.

5. Applying SINIS through an Action Research Action research (AR) is an approach to take action and also build knowledge about that action. An Action Research cycle is composed by a preliminary phase to understand context and objectives; a main stage to collect, validate and analyze data, plan, implement and evaluate actions; and a central phase to monitor all the work [COUGHLAN AND COUGHLAN, 2002].

\subsection{Action Research Motivation and Preliminary Phase}

This preliminary phase aimed at identifying the research context and purpose. This work took place within IT Security department of a large global organization A. IT Security Department provides IT services for all other departments of organization following ITIL practices [TSO, 2011]

IT Security department scenario motivated the SINIS evolving, since the first version was not completely suitable for an organization that had already started measurement. SINIS was created to allow IT Services departments review existent indicators, goals and strategies and discard indicators and strategies not aligned to goals, reducing waste of time and cost. IT Security manager informed his team spend too much effort to perform measurements not aligned to strategic organizational goals. Thus, team members didn't know why they are spending so much time on measurement activities and were losing motivation and trust on measurement results. Although the team had a large list of measures collected, members didn't know how these measures were related to the any goal, and neither how to interpret measurement results.

The researcher that conducted the action research study works in the IT Services directory but in Hosting department, a different subarea, being external to the context. The following phases proposed by Action-Research method were performed: data gathering, feedback and analysis; action planning, implementation and evaluation.

\subsection{Action Research Main Phase}

This study attended a request from the IT Security manager to review existent indicators. At that time, researcher had created first version of SINIS and was studying possible improvements to SINIS. Data gathering, actions planning and execution will be distributed through SINIS procedures as follows. Feedback and lessons learned will be presented in Action Research Feedback and Lessons Learned section.

(i) Elicit IT Services Context Factors and Assumptions: Relevant context factors and assumptions were identified from organizational goals and provided department documents. Context factor 1 was that Organization A first goal is to reduce costs. Related assumption was that IT Security cannot increase costs. Context factor 2 was that IT Security Area does not have people dedicated to measurement activities, and related assumption was Members of IT Security area will responsible for collecting and storing data for indicators and present results in weekly meeting to manager.

(ii) Review and Define IT Service Goals: IT Security area did not have a list documented IT services goals. IT Security manager wanted the team to define their own IT security goals and review existent indicators, and present him to validate. The team 
was not used to think about goals, they were used to collect and report operational measures. There was not a list of IT Service Goals to be used and there were defined. This was the longest activity because team was not used to think about goals. SINIS questions to support elicitation of IT Service Goals were used to guide brainstorms and 10 IT services goals were documented: Reduce the cost with IT Security incidents solution; Reduce the resolution time for IT Security incidents; Increase efficiency in controls execution; Reduce number of users with elevated access to Internet; Increase efficiency of blocking malware messages; Reduce the number of users with SAP SOD conflict; Increase IT Security team productivity; Maintain applications adherence to IT Security policies; Increase vulnerability detection and remediation and Increase efficiency of workstations and servers protection. An example of one of those IT services goals created was "Reduce the Cost with IT Security Incidents Solution".

(iii) Review and Define Indicators for IT Services: IT Security coordinator provided a list of 39 existent measures being collected in the department at the time, with no measurement plan or interpretation model. Although IT Security coordinator called this list as Indicators List, it should be a Measures List, as there was not any alignment between measures and goals. Next step was to find connection between each indicator and an IT Service Goal. One example of how association was the indicator "Manual resolution rate" associated to IT security goals "Reduce the cost with IT Security incidents solution" and "Reduce the Resolution Time for IT Security Incidents". Indicators and goals were reviewed to discard those ones not associated to any goal. Seven indicators without any associated goal were discarded, no longer measured and existing indicators were renamed and documented following SINIS template.

(iv) Review and Elicit Strategies to Achieve IT Service Goals: IT Security coordinator did not have a list of documented strategies being executed to achieve IT services goals. The researcher considered this as expected, because the team did not have a defined list of goals to be achieved. The process mapping for processes related to IT services goals was the first step carried out in this activity. IT services goal indicator "Percentage of antivirus incidents where field intervention was necessary to solve the issue (manual/total)" was selected to have strategies defined during this research.

By using process mapping, we could already find that incident manual resolution happens when IT Security is not able to automatically remove a threat and neither remotely solve it. Those two are the unwanted conditions to be focused during rootcause analysis. According to investigation, cause of not being able to perform remote access is related to an error default installation of users' workstations, which is missing to enable Remote Procedure Call. Root-cause was focused by strategies in next activity.

The antivirus expert informed he contacted the area responsible for installing users' workstations about the issue and the strategy will consist of providing (i) a new installation image, and (i) a script to enable and start Remote Procedure Call in every restart s. Strategy was documented following SINIS Template for Strategies

(v) Review and Define Indicators for IT Service Strategies: Information needed was number of times that remote support was not done in default workstations caused by Remote Procedure Call not being enabled. COBIT Process sample measures and IT Services list of measures were consulted, but there was no available measure for reuse. 
(vi) Create or Review Interpretation Models for all Indicators: Interpretation models for related indicators were created, as shown in Table 6 , to determine how collected data should be interpreted and drive decision-making.

Table 6 - SINIS Interpretation Model for IT Services' Goal and Strategy Indicators

\begin{tabular}{|c|c|c|}
\hline & $\begin{array}{c}\text { SINIS Interpretation Model for IT } \\
\text { Services' Goal }\end{array}$ & $\begin{array}{c}\text { SINIS Interpretation Model for } \\
\text { Strategy Indicator }\end{array}$ \\
\hline $\begin{array}{l}\text { Indicator } \\
\text { related }\end{array}$ & $\begin{array}{l}\text { Percentage of antivirus incidents where field } \\
\text { intervention was necessary to solve the issue } \\
\text { (manual/total) }\end{array}$ & $\begin{array}{l}\text { Percentage of manual antivirus incidents } \\
\text { where remote support failed due to } \\
\text { Remote Procedure Call was not enabled }\end{array}$ \\
\hline Target & $20 \%$ & $10 \%$ \\
\hline Range & Reduction & Reduction \\
\hline Baseline & $60 \%$ last year & $40 \%$ last year \\
\hline Model & $\begin{array}{l}\text { If value is } 5 \% \text { over target, only verify isolated } \\
\text { cases. If value is more than } 6 \% \text { over target, } \\
\text { review root-cause and strategies in place. }\end{array}$ & $\begin{array}{c}\text { If value is } 5 \% \text { over target, only verify } \\
\text { isolated cases. If value is more than } 6 \% \\
\text { over target, review implemented strategy. }\end{array}$ \\
\hline Responsible & IT Security antivirus responsible & IT Security antivirus responsible \\
\hline Moment & $\begin{array}{l}\text { Every month, starting one month after End } \\
\text { User team completes strategy }\end{array}$ & $\begin{array}{c}\text { Every month, starting one month after End } \\
\text { User team completes strategy }\end{array}$ \\
\hline Periodicity & $\begin{array}{l}\text { Every month, current value is compared to } \\
\text { target and to previous month as a reference. In } \\
\text { the end of the year, total value is compared to } \\
\text { total value in the previous year. }\end{array}$ & $\begin{array}{c}\text { Every month, current value is compared to } \\
\text { target and to previous month as a } \\
\text { reference to verify if strategy was } \\
\text { successful. }\end{array}$ \\
\hline
\end{tabular}

(vii). Build, review and adjust GQM+Strategies Grid: The researcher organized context factors, assumptions, goals, strategies and indicators in a GQM+Strategies grid and presented it to all IT Security team to gather members' opinion and concerns and extend the work to all other indicators with respective responsible (Figure 3).

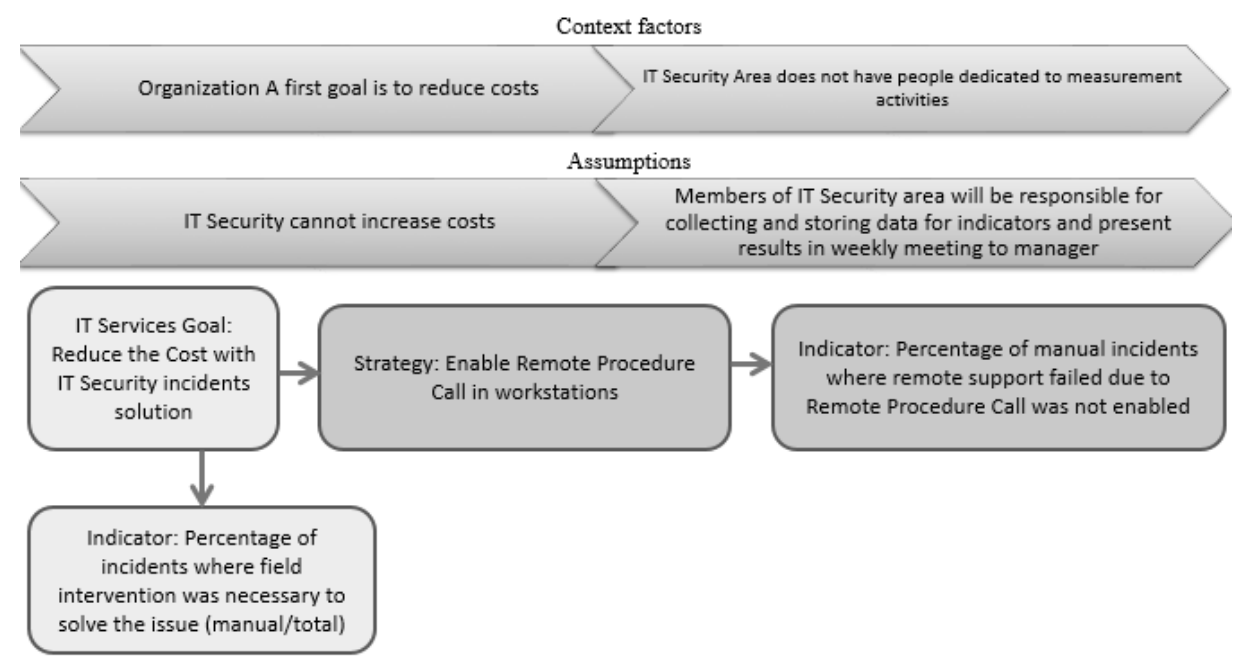

Figure 33 - GQM+Strategies grid

\subsection{Action Research Threats to Validity}

We now discuss some threats to validity, following concepts of Conclusion Threats, Internal Threats, Construction Threats and External Threats [WOHLIN et al., 2012].

An external threat is about the number of cases we applied the method. SINIS was applied in only two scenarios: First version was applied in IT Infrastructure department 
(TRINKENREICH et.al, 2015c), we have evolved based on feedbacks and presented the second version in this paper, applying to IT Security department. This can affect generalizing results as SINIS was not applied to several scenarios. The manager had a short due date given by director and IT Security team did not have enough available time to completely execute SINIS. Only one strategy and respective indicator and interpretation model were created during the experience. During process mapping, Measurement, Method and Manpower causes were not investigated. This was considered an internal threat because the moment when researcher applied the method to IT Security team could be not very appropriated, as the team was on a rush to review indicators as requested by director. A conclusion threat was related to researcher. Even being another department, she works in the same Organization, and so has already a previous knowledge about business goals and general processes and also could have manipulated any data. In order to minimize those threats, we have fully created an interpretation model for selected strategy indicator and related IT Service goal, IT Security members learned about SINIS concepts and procedures to replicate and define for all others indicators. Besides that, SINIS includes instruments (procedures, checklists, templates and examples) to guide execution by other researchers, being possible to replicate results in other Organizations by other researchers. An internal threat was about defining targets for indicators. IT Security manager asked the team to decide about indicators targets. The usage of indicators' targets was a new concept for IT Security members and they were afraid of increasing workload. In order to minimize this threat, IT Security manager decided to review targets and to use this opportunity to discuss workloads with the team. A construction threat was about using COBIT Goals Cascade. Examples for reuse were consulted but not used, so we could validate if they are really useful or can provide insights and reduce time during indicators selection.

\subsection{Action Research Feedback and Lessons Learned}

IT Security coordinator was stated that after IT Security team is now more dedicated to measurement activities, as they understand the relationship with IT services goals. Also, he informed that interpretation models and strategies were new concepts for him and for the team, and that team was motivated to complete the creation of respective indicators (following what was done by the antivirus responsible), although he showed concern on the amount of required time to dedicate on that.

During the case study the researcher observed positive and negative lesson learned. Although reusing IT services goals provides inspiration for an organization not used to think about goals to be achieved, searching a catalog wasis not effective for an organization withthat does already have a large list of measures in place and needings to reduce time and cost during indicators selection. Having root cause investigation to derive goals in strategies is effective to select actions that can directly solve issues, instead of working in many possible (and not targeted) initiatives. But SINIS do not explicitly support choosing the most suitable root-cause technique. Therefore, future SINIS versions should contemplate it. We found that SINIS templates and examples helped and saved execution time, but more information might be needed for a person not very familiar to IT services process when applying SINIS data collection. As future work, we intend to create checklists and a case tool with forms based on templates and tips based on those checklists and examples to facilitate following SINIS procedures. 


\section{RELATED WORKS}

COBIT Goals Cascade provides a large catalog of goals and indicators to be reused for IT Services organizations. However, COBIT Goals Cascade recommends that each organization should build its own goals cascade, compare it with COBIT Goals Cascade's and then refine it [ISACA, 2012], and does not provide a mechanism to drive this building. SINIS is covering this gap by providing procedures, checklists, templates and examples to be followed for an IT Services organization to define its own goals and indicators, while accessing COBIT Goal Cascade catalog for reuse. GQM+Strategies indicates that goals, measures and strategies should be aligned and modeled in a grid is to support making goals and strategies explicit for an organization and to provide a clear correlation of all measurement initiatives [BASILI et al., 2005]. However, GQM+Strategies does not detail how to identify critical processes to be considered in strategies or how to define proper strategies and measures. SINIS is covering this gap by providing analysis of critical processes, which includes mapping and identifying critical sub-processes in processes related to IT services goals and finding root-cause for issues.

We could not find an approach that instantiates building GQM+Strategies grid specifically for IT Services with a macro-process, procedures, checklists, templates and examples like SINIS, but there are other researches that also apply GQM+Strategies and discuss gaps that were addressed by SINIS. There are some proposals that although not devoted to IT services, can be used in this context. LÓPEZ et al. (2016), KANEKO et al. (2011) provide lessons learned, results and experiences from applying GQM+Strategies approach in industry, but authors did not suggest any kind of method, neither procedures to be used when applying GQM+Strategies to other cases. ASGHARI (2012) used action research and proposed an elicitation approach to support collecting information for goals and strategies to apply GQM+Strategies in an organization. Author considered that there is a need to conduct more empirical research on GQM+Strategies as the approach so far was evaluated in few cases.

Even not related to GQM+Strategies, we could not find many other researches that also address selection of indicators for IT services measurement. A framework for measuring IT services was presented by LEPMETS et al. (2011) and validated in industry [LEPMETS et al., 2014], but only a catalog is provided, not a method to define and select measures, and align them to business goals. Authors state that alignment between business objectives and IT services industry needs to be studied and could provide additional support for their framework. JÄNTTI et al. (2011) presented a support system to IT Services Measurement. In addition to a well-designed and easy to use measuring tool, there is a need for a systematic measurement process, and measures need to be based on business goals.

\section{FINAL CONSIDERATIONS}

This paper presented SINIS, a method to help organizations select indicators for IT services in multiple levels in alignment to business goals and to support organizations on measuring only what matters, abandoning ineffective measurements. SINIS can be used either when organization has an existent group of indicators in place or not. When it has , SINIS can support to review and align those indicators to goals, and then be able to report correct data to the more appropriated stakeholder for decision-making. 
SINIS was applied to IT Security area of a global large company in which a large set of measures was being collected, but the manager was not sure about their utility in decision-making. Research question "How to support alignment of IT services indicators with organization goals to measure only what really matters?" was answered by using SINIS, because IT Security area could better understand and document indicators, associate them to business goals and strategies, discard those ones that were not considered useful, create new ones, building the GQM+Strategies grid. Even having only one experience and not being able to statistically and effectively prove SINIS applicability, there is evidence that the method is able to provide support during indicators definition for IT Services departments. Researcher collected lessons learned to validate some decisions about SINIS procedures and improve SINIS in future.

\section{Acknowledgements}

Authors thank CAPES, FAPERJ (E-26/210.643/2016, E-211.174/2016), CNPq (Process 461777/2014-2) and UNIRIO (project PQ-UNIRIO 01/2016 and 01/2017) for their financial support.

\section{References}

BARCELlOS, M. P., FALBO, R.D., ROCHA, A.R., 2012, "Using a Reference Domain Ontology for Developing a Software Measurement Strategy for High Maturity Organizations" 16th IEEE International Enterprise Distributed Object Computing Conference p.114

BARR, S., 2014, "Practical Performance Measurement Using the PuMP Blueprint for Fast, Easy and Engaging Performance Measures

BASILI, V., TRENDOWICZ, A., KOWALCZYK, M., HEIDRICH, J., SEAMAN, C., MÜNCH, J., ROMBACH D., 2005, "Aligning Organizations Through Measurement - The GQM+Strategies Approach" Springer

BROOKS, P., 2006, “Measures for IT Service Management”. Van Haren, UK

COUGHLAN, P., COUGHLAN, D., 2002 "Action research for operations management". International journal of operations \& production management, v22

DRUCKER, P. F., 1954, “The Practice of Management”. Harper Collins, New York

FORRESTER, E., BUTEAU, B., SHRUM, S., 2010, "CMMI For Services, Guidelines for Superior Service. CMMI-SVC Version 1.3", - 2nd Edition. SEI. AddisonWesley Professional

JÄNTTI , M., LAHTELA, A., KAUKOLA, J., 2010, "Establishing a Measurement System for IT Service Management Processes: A Case Study". International Journal on Advances in Systems and Measurements, vol 3 no 3 \& 4

KANEKO, T., KATAHIRA, M., MIYAMOTO, Y., KOWALCZYK, M., 2011, "Application of GQM+Strategies in the Japanese Space Industry" International Workshop on Software Measurement

KAPLAN, R., NORTON, D.P., 1996, "The Balanced Scorecard Translating Strategy Into Action". Havard Business School Press, Boston 
KILPI, T., 2001, "Implementing a software measures program at Nokia", IEEE Software. Volume18, issue 6, pp. 72-77. ISSN: 0740-7459

LEPMETS, M., RAS, E., \& RENAULT, A., 2011, “A Quality Measurement Framework for IT Services”. In Annual SRII Global Conference, San Jose, CA. pp. 767-774

PARMENTER, D., 2015, "Key Performance Indicators - Developing, Implementing and Using Winning KPIs" 3rd Edition Wiley

PETERSEN, K., GENCEL, C., ASGHARI, N., BETZ, S., 2015, An elicitation instrument for operationalizing GQM+Strategies (GQM+S-EI)". Empirical Software Engineering, vol. 20 no. 4

SANTOS, THIAGO MARCONDES, 2015, “Computação Ubíqua para apoiar a educação musical: explorações com o Makey Makey". Master Degree Dissertation, UNIRIO. 195pp.

SOFTEX, 2015. "MPS.BR - Guia Geral MPS de Serviços”. www.softex.br

TSO. ITIL Service Operation, 2011.

TRINKENREICH, B., SANTOS, G., 2014, "Evaluation of measurement process for incidents, continuity and availability management under the light of MR-MPS-SV maturity model", $10^{\text {th }}$ Annual workshop for software and services Quality improvement (WAMPS), Campinas, Brazil

TRINKENREICH, B., SANTOS, G., BARCELLOS, M., 2015a, "Measures to Support IT Service Maturity Models - A Systematic Mapping Study", 17th International Conference on Enterprise Information Systems (ICEIS), Barcelona, Spain

TRINKENREICH, B., SANTOS, G., 2015a "Measures to Support IT Service Maturity Models - A Case Study", 17th International Conference on Enterprise Information Systems (ICEIS), Barcelona, Spain

TRINKENREICH, B., SANTOS, G., CONFORT, V., SANTORO, F., 2015b, “Toward using Business Process Intelligence to Support Incident Management Measures Selection and Service Improvement". 27th International Conference Software Engineering Knowledge Engineering, Pittsburg, USA

TRINKENREICH, B., SANTOS, G., 2015b, "Evaluation of incident management process under the light of MR-MPS-SV maturity model and measurement to support IT Service quality improvement", $14^{\text {th }}$ Software Quality Brazilian Conference (SBQS), Manaus, Brazil

TRINKENREICH, B., SANTOS, G., BARCELLOS, M., 2015c, "SINIS - A Method to Select Indicators for IT Services", $16^{\text {th }}$ International Conference on ProductFocused Software Process Improvement (PROFES), Bolzano, Italy.

WOHLIN, C., RUNESON, P., HÖST, M., REGNELL, B., WESSLÉN, 2012. Experimentation in Software Engineering, Springer, ISBN: 978-3642290435. 